\title{
The assessment of the malnutrition in traumatic ICU patients in Iran
}

\author{
Hosein Kimiaei-Asadi ${ }^{1}$, Arya Tavakolitalab ${ }^{2}$
}

${ }^{1}$ MD, Anesthesiologist, Associate Professor, Department of Anesthesiology, Faculty of Medicine, Hamadan University of Medical Sciences, Beesat Hospital, Hamedan, Iran

${ }^{2}$ M.Sc. in Nutrition, Lecturer of University of Comprehensive Scientific of Hamadan Province, Hamadan, Iran

\section{Type of article: Original}

\begin{abstract}
Background: Despite recognition of the importance of nutritional feedings, the delivery of optimal nutrition remains difficult to achieve in most intensive care units (ICU).

Objective: To assess the status of malnutrition in traumatically ill patients hospitalized in an ICU in Iran.

Methods: This descriptive, cross-sectional study was conducted in Hamadan, Iran, on 123 patients in an ICU ward over six months with the purpose of assessing malnutrition status. Malnutrition and its severity were assessed based on the defined chemical parameters on admission and the end of stay times. Also, body mass index (BMI), weight (W), and height $(\mathrm{H})$ anthropometric indices were assessed simultaneously to be compared with the chemical results. For statistical analysis we used SPSS version 16 software.

Results: Overall, $83 \%$ of patients had malnutrition on admission to ICU, which was $90 \%$ on discharge or neardeath condition, indicating increase of the prevalence of malnutrition within hospitalization in this ward. On admission, $11 \%$ of patients had mild, $61 \%$ moderate, and $11 \%$ severe malnutrition that reached to $4 \%, 63 \%$, and $23 \%$, respectively, by the end of the stay. BMI was significantly different in the patients who completed two weeks in the ICU $(p<0.05)$. Assessment of the correlation between admission and two week completed stay showed that BMI, H, and W were positively correlated $(\mathrm{r}=0.85),(\mathrm{r}=1.0)$, and $(\mathrm{r}=0.638),(\mathrm{p}<0.05)$, respectively. There were no significant correlations in these parameters in the fourth week. Assessing the changes in anthropometric parameters showed downward trends of both weight and body mass index within ICU hospitalization.

Conclusion: As shown in our study, inattention to needs of critically ill patients or lack of facilities results in developing and worsening of malnutrition, which, in turn, considerably worsens the outcome. To supply the needs of these in-hypermetabolic state patients, the importance of nutrition and its effect on outcome must be understood by medical staff; close monitoring of the nutritional status of these patients, along with meticulous calculations and team work, must be done and appropriate supportive routs be used.

Keywords: Intensive Care Unit, Malnutrition, Nutritional Assessment, Patient
\end{abstract}

\section{Introduction}

Malnutrition is common in hospitalized patients, especially in post-traumatic patients in intensive care units (ICU) (1). Contrary to critically ill patients admitted to ICU following advanced internal or surgical problems such as prolonged cancer, metabolic diseases, or respiratory problems, traumatic patients are considered healthy before trauma and admission to ICU and thus may show the effect of ICU care on their nutritional conditions better. Mortality rate in the ICU has been reported at $5 \%$ to $35 \%$, while this is $18.1 \%$ to $29.3 \%$ in other wards (2). In studies, about two-thirds of ICU patients are malnourished (3). It is obvious that these patients need more energy and nutrients compared with normal individuals and simple condition patients to improve and achieve a normal situation (4). Nutritional support should be considered for patients who are already undernourished, have not

\section{Corresponding author:}

Associate Professor Dr. Hosein Kimiaei-Asadi, Department of Anesthesiology, Faculty of Medicine, Hamadan University of Medical Sciences, Beesat Hospital, Hamedan, Iran.

Tel: 0098-918-1111606, Email: hkimiaeimd@yahoo.com

Received: September 03, 2016, Accepted: April 12, 2017, Published: June 2017

iThenticate screening: April 15, 2017, English editing: May 26, 2017, Quality control: June 11, 2017

(C) 2017 The Authors. This is an open access article under the terms of the Creative Commons Attribution-NonCommercialNoDerivs License, which permits use and distribution in any medium, provided the original work is properly cited, the use is non-commercial and no modifications or adaptations are made. 
received food for five to seven days, diseased for more than 10 days, or are in a hypermetabolic state. There is usually one or more of these in traumatic patients during hospitalization, and so almost all ICU patients should receive meticulous nutritional support (5). Despite more requiring nutritional support in traumatic patients admitted to intensive care units, adequate nutrition in these patients in a notable number of care units has been reported to be suboptimal. The main reason for more patients needing nutritional support is due to the increased level of metabolic demands compared with normal individuals (6). Thus, in patients faced with malnutrition, not only lower nutrition and energy supply can result in inadequate response to needs of body vital organs, but also there's more adverse events such as increased infectious complications and higher mortality when compared with patients who receive adequate nutrition (7-8). Despite recognition of the importance of nutritional feedings, the delivery of optimal nutrition remains difficult to achieve in most ICUs (9). As directly responsible for treating patients in ICU, we witnessed cachexia and malnutrition after some time, which is the rationale for investigating the condition followed by suggesting appropriate solutions and early intervention. The present study aimed to assess the status of malnutrition in traumatic patients hospitalized in ICUs in Iran.

\section{Material and Methods}

This descriptive cross-sectional study was carried out in Hamadan, Iran, in 2009 on 123 patients in the ICU ward for six months. All patients were admitted to the ICU in Mobasher Kashani Hospital, the center of trauma in Hamadan Province, were included, whom almost all traumatic. Only patients remaining less than 24 hours were excluded because the impact of nutrition on them was not considerable. Immediately after admission to the ICU, the nutritional status of patients was assessed and categorized by a nutrition expert using chemical parameters (10). In addition, anthropometric indices, including weight, height, and body mass index (BMI), were also assessed upon admission (11). These at time zero measurements were used as a base line with which further measurements could be compared. These initial measurements also showed the nutritional condition of patients on admission, just before trauma. Malnutrition status and anthropometric indices were assessed weekly and at discharge or near-death time to analyze their excursion and the patient's nutritional support efficacy. Results were presented as mean \pm standard deviation (SD) for quantitative variables and were summarized by frequency (percentage) for categorical variables. The trend of the changes in quantitative variables was measured using the repeated measure ANOVA test. Also, the correlation was used to determine the relationship between variables on admission and discharge times. For the statistical analysis, the statistical software SPSS version 16.0 was used. P-values of 0.05 or less were considered statistically significant.

\section{Results}

Our study population included 98 men and 25 women in whom four patients were under 20 years old, 25 patients 20-50 years old, and 94 patients older than 50 years. Of 123 patients, 93 were hospitalized less than one week, 18 for two weeks, seven for three weeks, and five for four weeks. There was no statistical difference in terms of the age and sex in these weeks. Overall, $83 \%$ of patients had malnutrition on admission to ICU; however, the prevalence of malnutrition on discharge from ICU or near-death conditions was $90 \%$, thus indicating increase of the prevalence of malnutrition within hospitalization in ICU ward. On admission time, 11\% of patients had mild, $61 \%$ moderate, and $11 \%$ severe malnutrition that reached to $4 \%, 63 \%$, and $23 \%$ respectively on the end of ICU stay (Table 1 ).

Table 1. Malnutrition status in trauma ICU patients on admission and discharge or near-death conditions

\begin{tabular}{|l|l|l|l|}
\hline Malnutrition & $n$ & $\%$ \\
\hline On admission & Non & 20 & 16.26 \\
\cline { 2 - 4 } & Mild & 14 & 11.38 \\
\cline { 2 - 4 } & Moderate & 75 & 60.97 \\
\cline { 2 - 4 } & Severe & 14 & 11.38 \\
\cline { 2 - 4 } & Malnutrition-T & 103 & 83.74 \\
\hline At discharge or near death & Non & 11 & 8.94 \\
\cline { 2 - 4 } & Mild & 5 & 4.06 \\
\cline { 2 - 4 } & Moderate & 78 & 63.4 \\
\cline { 2 - 4 } & Severe & 29 & 23.6 \\
\cline { 2 - 4 } & Malnutrition-T & 112 & 91.06 \\
\hline
\end{tabular}

Similarly, a significant downward trend was also revealed in mean weight from $52.42 \pm 5.19 \mathrm{~kg}$ on admission to $45.44 \pm 1.36 \mathrm{~kg}$ on the end of ICU stay. In this regard, mean weight loss was $3.0 \mathrm{~kg}$ within the first week, $0.86 \mathrm{~kg}$ 
within the second week, $1.63 \mathrm{~kg}$ within the third week, and $1.49 \mathrm{~kg}$ within the fourth week of hospitalization (Table 2). Assessing the changes in anthropometric parameters showed that the mean BMI on admission was $18.56 \pm 2.25$ $\mathrm{kg} / \mathrm{m} 2$, which reached to $15.98 \pm 2.05 \mathrm{~kg} / \mathrm{m} 2$ at fourth week of admission with a significant decreasing trend (Figure 1, Table 2). BMI was significantly different in patients who stayed completed two weeks in the ICU ward ( $<<0.05$; Table 3) but didn't have significant different in comparison between admission time with the fourth week of stay in ICU.

Table 2. Evaluation of variations in traumatic patients

\begin{tabular}{|l|l|l|l|l|}
\hline Anthropometric characteristics anthropometric & $n$ & BMI $\left(\mathrm{kg} / \mathrm{m}^{2}\right)^{*}$ & Weight $(\mathrm{kg})$ & Height $(\mathrm{m})$ \\
\hline Admission & 123 & $18.55 \pm 1.29$ & $52.42 \pm 5.19$ & $1.68 \pm 0.07$ \\
\hline First week & 123 & $17.49 \pm 1.15$ & $49.42 \pm 4.99$ & $1.67 \pm 0.07$ \\
\hline Second week & 18 & $17.13 \pm 1.44$ & $48.55 \pm 3.88$ & $1.68 \pm 0.22$ \\
\hline Third week & 7 & $16.47 \pm 0.7$ & $46.93 \pm 2.65$ & $1.69 \pm 0.23$ \\
\hline Fourth week & 5 & $15.98 \pm 1.0$ & $45.44 \pm 1.36$ & $1.68 \pm 0.28$ \\
\hline
\end{tabular}

*BMI: body mass index

Table 3. Comparison mean (repeat measure ANOVA) in BMI and between weight-in and weight-out

\begin{tabular}{|l|l|l|l|l|}
\hline Repeated measures ANOVA & 2 Week & & 4 week & \\
\hline & $t$ & $p$-value & $t$ & $p$-value \\
\hline BMI & 8.83 & $<0.05^{*}$ & 2.99 & 0.058 \\
\hline
\end{tabular}

*comparing mean is significant at the 0.05 level.

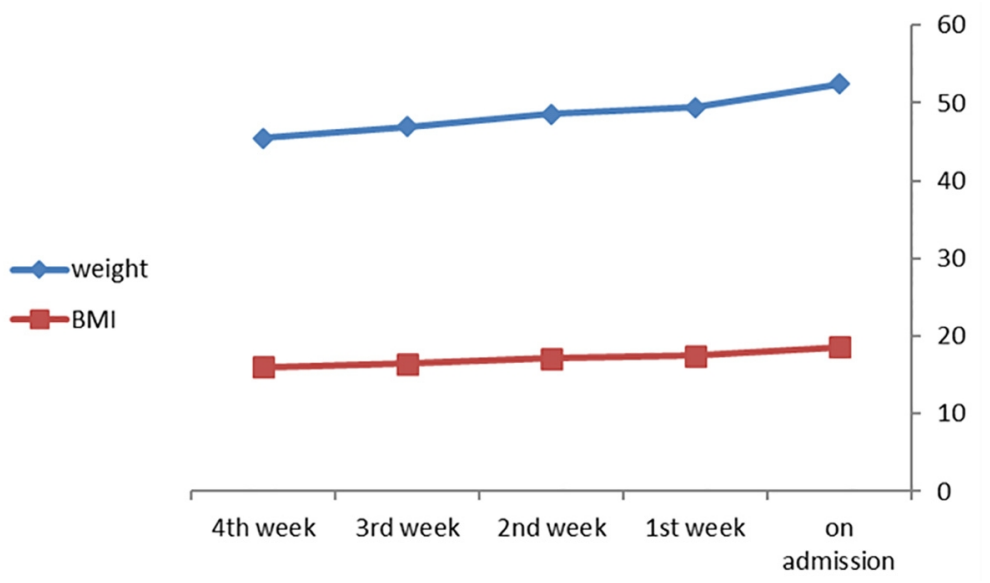

Figure 1. Trend of the changes in anthropometric parameters within hospitalization

\section{Discussion}

As we know, trauma patients are in hypermetabolic state with even more than normal nutritional needs, indicating going over the patient with meticulous calculations to compensate these needs. It is obvious that nutritional support of these patients can considerably affect their outcome. Many critically ill patients hospitalized in ICU wards may have been initially suffering an illness and have had poor nutrition before admission to intensive care (12). Because of a limited nutrition reserve, these patients have a poorer outcome. A low BMI has been shown to be an independent predictor of excess mortality in multiple organ failure (13). In our study, the prevalence of malnutrition on admission was about $84 \%$ of which $11 \%$ of patients had mild, $61 \%$ moderate, and $11 \%$ severe malnutrition. Nutritional status of patients on admission is interesting. If it is supposed that traumatic patients had been healthy before trauma with no debilitating disease, presence of malnutrition on admission, including considerable moderate and severe divisions, could be attractive for public health authorities and nutrition experts. The prevalence of malnutrition was increased to $91 \%$ at the end of stay in the ICU with a shift from mild and moderate to severe: $4 \%$, $63 \%$, and $23 \%$, respectively. A recent study on operated patients in Iran showed that patients in the ICU are malnourished, and assessment of anthropometric parameters has more favorable results than chemical (14). We assessed anthropometric indices BMI, weight, and height simultaneously; downward trends of which are favorable with chemical results and corroborative of nutritional status worsening in our patients. It has been shown that regular measurement of malnutrition in child critically ill patients is necessary to remain healthy (15). A study on ICU 
patients released by Azad et al. conducted in 2011 showed similar results as ours; their patients needed nutritional support, too (16). Our study shows progressive worsening of malnutrition status as ICU stay continues; this, in turn, reveals inattention of medical staff, especially physicians responsible for patients to their nutritional status and also its importance and effect on outcome. Strong design and use of standard parameters in our study resulted in achieving punctual information about the nutritional status of patients in our trauma ICU and revealed important masked defects in the treatment of them. The most important weak point of our study was the low number of cases, as only seven patients reached the third, fourth, and fifth week of ICU stay; thus, stronger studies may result in more accurate results.

\section{Conclusions}

Unfortunately, all results are consistent with each other, indicate an increased prevalence and severity of malnutrition in hospitalized patients from the beginning of hospitalization to discharge in the ICU ward. These observations need to predict necessary nutrition for these patients after discharge shows (which are primarily surgical procedures such as gastrostomy). To achieve fully qualified nutritional support, the importance of nutrition in critically ill patients must be understood by all medical staff, especially physicians. The next steps are multidisciplinary treatment of these patients, including from nutrition experts who should regularly monitor the patient's nutritional status from admission and make meticulous calculations to supply daily needs and compensate deficits if present, having desired facilities and using appropriate routs of nutrition; it seems that almost all have been lacked in our ICU, unfortunately.

\section{Acknowledgments:}

We want to express our appreciation to the vice chancellor for research and technology, Hamadan University of Medical Sciences, for support of the project. We offer our sincere thanks and gratitude to the Institute of Nutrition and Food Technology at Shahid Beheshti University of Medical Sciences, Mobasher Kashani Hospital ICU staff.

\section{Conflict of Interest:}

There is no conflict of interest to be declared.

\section{Authors' contributions:}

Both authors contributed to this project and article equally. Both authors read and approved the final manuscript.

\section{References:}

1) Sungurtekin H, Sungurtekin U, Oner O, Okke D. Nutrition assessment in critically ill patients. Nutr Clin Pract. 2008; 23: 635-41. doi: 10.1177/0884533608326137. PMID: 19033223.

2) Jacobs S, Arnold A, Clyburn PA, Willis BA. The Riyadh intensive care program applied to a mortality analysis of a teaching hospital intensive care unit. Anaesthesia. 1992; 47(9): 775-80. doi: 10.1111/j.13652044.1992.tb03255.x. PMID: 1415974.

3) McWhirter JP, Pennington CR. Incidence and recognition of malnutrition in hospital. BMJ. 1994; 308(6934): 945-8. doi: 10.1136/bmj.308.6934.945. PMID: 8173401, PMCID: PMC2539799.

4) Abbott WO, Rawson J. A Tube For Use In The Potoperative Care Of Gastro-Enterostomy Patients-A Correction. JAMA. 1939; 112(23): 2414. doi: 10.1001/jama.1939.62800230005012c.

5) Guidelines for use of total parenteral nutrition in the hospitalized adult patient. A.S.P.E.N. Board of Directors. JPEN J Parenter Enteral Nutr. 1986; 10(5): 441-5. doi: 10.1177/0148607186010005441. PMID: 3093699.

6) Petros S, Engelmann L. Enteral nutrition delivery and energy expenditure in medical intensive care patients. Clin Nutr. 2006; 25(1): 51-9. doi: 10.1016/j.clnu.2005.08.013. PMID: 16216393.

7) Alberda C, Gramlich L, Jones N, Jeejeebhoy K, Day AG, Dhaliwal R, et al. The relationship between nutritional intake and clinical outcomes in critically ill patients: results of an international multicenter observational study. Intensive Care Med. 2009; 35(10): 1728-37. doi: 10.1007/s00134-009-1567-4. PMID: 19572118.

8) Herridge MS, Cheung AM, Tansey CM, Matte-Martyn A, Diaz-Granados N, Al-Saidi F, et al. One-year outcomes in survivors of the acute respiratory distress syndrome. N Engl J Med. 2003; 348(8): 683-93. doi: 10.1056/NEJMoa022450. PMID: 12594312.

9) Cahill NE, Dhaliwal R, Day AG, Jiang X, Heyland D. Nutrition therapy in the critical care setting: what is "best achievable" practice? An international multicenter observational study. Crit Care Med. 2010; 38(2): 395-401. doi: 10.1097/CCM.0b013e3181c0263d. PMID: 19851094. 
10) Rippe JM, Irwin RS. Intensive Care Medicine. 2th ed. 1991.

11) kathleen Mahan, MS,RD, CDE. Sylvia EScott Stump,MA,RD,LDN: Enteral and Parenteral Nutrition Support in food nutrition and Diet Therapy. 2000; 533-533.

12) Giner M, Laviano A, Meguid MM, Gleason JR. In 1995 a correlation between malnutrition and poor outcome in critically ill patients still exists. Nutrition. 1996; 12(1): 23-9. doi: 10.1016/08999007(95)00015-1.

13) Galanos AN, Pieper CF, Kussin PS, Winchell MT, Fulkerson WJ, Harrell FE Jr, et al. Relationship of body mass index to subsequent mortality among seriously ill hospitalized patients. SUPPORT Investigators. The study to understand prognoses and preferences for outcomeand risks of treatments. Crit Care Med. 1997; 25(12): 1962-8. doi: 10.1097/00003246-199712000-00010. PMID: 9403743.

14) Hejazi N, Mazloom Z, Zand F, Rezaianzadeh A, Amini A. Nutritional Assessment in Critically Ill Patients. Iran J Med Sci. 2016; 41(3): 171-9. PMID: 27217600, PMCID: PMC4876294.

15) Saharan S, Lodha R, Kabra SK. Supportive Care of A Critically Ill Child. Indian J Pediatr. 2011; 78(5); 585-92. doi: 10.1007/s12098-010-0352-2. PMID: 21193972.

16) Daneshzad E, Azadbakhat L, Neamani F, Abasi S, Shirani F, Adibi P. Nutritional Assessment of ICU impatients in Alzahra Hospital. J Health Syst Res. 2014; 10(4): 655-68 